Perspectiva de Familia (Perspect. fam.) ISSN 2415-5187, año 2018, vol. 3, pp. 45-78

\title{
Impacto de la familia en el trabajo: Un estudio predictivo de trabajadores de una universidad privada de Arequipa
}

Family impact in work: a predictive study of employees from a private university in Arequipa

Walter L. Arias Gallegos, Karla D. Ceballos Canaza, Alessandra Román Gallardo, Claudia Maquera Fernández y Atena Sota Velásquez Universidad Católica San Pablo, Arequipa, Perú

Recibido: 07-03-18

Aceptado: 15-06-18

\section{Resumen}

En el presente artículo se valoran las relaciones entre la satisfacción marital, la satisfacción familiar, la integración familiar, la satisfacción laboral y el síndrome de burnout en 213 trabajadores (docentes y administrativos) de una universidad privada en Arequipa. Se utilizaron la Escala de Satisfacción Marital; la Escala de Satisfacción Familiar; el Inventario de Integración Familiar; la Escala de Satisfacción en el Trabajo de Warr, Cook y Wall; y el Inventario de Burnout de Maslach. Se ha encontrado que la satisfacción marital se relaciona con la satisfacción familiar y la integración familiar, y que la satisfacción familiar se relaciona con la satisfacción laboral. Se describen las diferencias en función del sexo, el cargo, el tiempo de servicio y los ingresos económicos. También se realizó un análisis de regresión que indica que la satisfacción marital, la satisfacción familiar y la integración familiar predicen la satisfacción laboral, mientras que la satisfacción familiar predice el síndrome de burnout.

Palabras clave: Conflicto familia-trabajo, satisfacción marital, satisfacción familiar, satisfacción laboral, integración familiar, síndrome de burnout. 


\begin{abstract}
In the present study we value the relationships between marital satisfaction, family satisfaction, family integration, job satisfaction, and burnout syndrome in 213 employees (academic and administrative personnel) from a private university in Arequipa. We use the Marital Satisfaction Scale, the Family Satisfaction Scale, the Family Integration Inventory, the Job Satisfaction Scale, and the Maslach Burnout Inventory. We found that marital satisfaction is correlated to family satisfaction and family integration, in addition, family satisfaction is related to job satisfaction. We also described differences by sex, charge in the organization, working time, and economical income. Moreover, we made a lineal regression that reported marital satisfaction, family satisfaction and family integration predicted job satisfaction. Meanwhile, family satisfaction predicted burnout syndrome.
\end{abstract}

Key words: Family-work conflict, marital satisfaction, family satisfaction, job satisfaction, family integration, burnout syndrome.

\title{
Introducción
}

Existen diversos factores que afectan la satisfacción laboral de los trabajadores. Entre ellos, podemos mencionar el clima organizacional (Salgado, Remeseiro e Iglesias, 1996) y diversas variables organizacionales, como la estructura de la empresa, las condiciones de trabajo, el ambiente laboral, el salario, la seguridad, el confort, las relaciones humanas entre los trabajadores, etc. (Gómez, Benítez, Guillén, Gala y Lupiani, 200o). En estudios previos, hemos podido encontrar que factores como el salario, la organización del trabajo, las posibilidades de ascenso y la satisfacción con la empresa pueden evidenciar diferencias significativas en la satisfacción laboral de los trabajadores de dos tiendas por departamento (Arias y Justo, 2013). Asimismo, de las variables que impactan en la satisfacción laboral, el clima organizacional ha demostrado ser un potente predictor de esta (Schneider \& Snyder, 1975), debido a que un clima de trabajo óptimo brinda apoyo emocional al trabajador porque sus relaciones interpersonales se fortalecen y amortiguan los efectos de los factores negativos que pudieran tener lugar en la organización (Arias, 2013a).

En otro estudio que realizamos en Arequipa, se reportó que el clima organizacional se relacionaba de manera baja con la satisfacción laboral, pero que las dimensiones de flexibilidad y reconocimiento del clima organizacional presentaban relaciones moderadas y altamente significativas con la satisfacción laboral de los trabajadores de una pequeña empresa del sector privado (Arias y Arias, 2014). En el estudio de Joyti (2013), las dimensiones de claridad, administración, políticas, espíritu de equipo e imagen institucional fueron las que mejor predijeron la satisfacción laboral y el compromiso de los profesores de cuatro universidades de la India. 
Por otro lado, así como los factores organizacionales impactan en la satisfacción laboral, también la satisfacción del trabajador puede influir en su desempeño laboral (Lwanga, Ndiwalana, Ssekabuko \& Bwire Mc, 2014) y revertirse en muchas de estas variables organizacionales, de manera tal que si un trabajador no está satisfecho puede tener accidentes laborales y contribuir al detrimento del clima organizacional de la empresa (Schultz, 1999). Así pues, la satisfacción laboral actúa como una bisagra entre las causas y las consecuencias que dinamizan los variados elementos que componen la vida organizacional de la empresa.

Por otro lado, una variable que está teniendo mayor relevancia en el contexto laboral es la vida familiar del trabajador, pues ambos aspectos, la familia y el trabajo, ocupan gran parte del tiempo de las personas y se relacionan con las decisiones más trascendentes de la vida del hombre. Así pues, ante el evidente conflicto de las funciones laborales y familiares, surgen propuestas que apuestan por una sinergia entre la familia y el trabajo (Granados, 2015), tomando como premisa que la segunda se debe a la primera, y no a la inversa, ya que la familia es fuente de capital social (Donati, 2015) y posee un valor relevante en diversas esferas de la vida económica de las naciones (Campiglio, 2015). En ese sentido, las estructuras familiares nucleares se han relacionado con el desarrollo económico (Riesco \& Arela, 2015) y el bienestar de las personas (Pliego \& Castro, 2015), tanto en el Perú como en otros países.

Aunque existe abundante información que respalda lo anteriormente expuesto, muy pocos estudios ponen énfasis en el papel que juega la familia en la satisfacción laboral del trabajador. Algunos reportes indican que, entre 11 y $25 \%$ de las personas señalan que las tensiones de la familia debilitan la capacidad para trabajar (Prado \& Del Águila, 2010). Pero el desequilibrio entre los roles familiares y laborales está mediado por diversas variables personales, como la autoeficacia, la personalidad, la tolerancia al estrés, etc. (Rubio, Osca, Recio, Urien \& Peiró, 2015). Todo ello nos hace ver que los aspectos familiares y laborales se encuentran íntimamente ligados $y$, por tanto, tales nexos deben ser objeto de estudio. A este tema se le conoce como conflicto trabajo-familia o conflicto familia-trabajo, según sean las circunstancias. En el primer caso, es el trabajo el que impacta en la familia, y en el segundo caso, ocurre lo contrario. Se trata, por tanto, de un fenómeno bidireccional que recientemente está siendo investigado como una fuente de riesgo psicosocial en el trabajo (Guerrero \& Puerto, 2007).

\section{Satisfacción marital}

Podemos definir la satisfacción marital como "la congruencia en las expectativas de los integrantes de la pareja, el desempeño, la autopercepción, la comunicación y una plena aceptación de las críticas de parte de los cónyuges" (Alvarado \& Cisne- 
ros, citados por Prado \& Del Águila, 2010, p. 43). Asimismo, se ha planteado que el éxito matrimonial depende de factores tales como la felicidad en el matrimonio de los padres, la duración del noviazgo, una adecuada educación sexual, una infancia feliz, ajuste y motivación para el matrimonio, igualdad étnica y religiosa, posición social y nivel educativo, edad, preferencias, intereses e ideologías similares (Lukas, 2010). Sin embargo, un factor que puede afectar el ajuste de la pareja y su consecuente satisfacción es el balance que se establezca entre las vidas familiar y laboral.

El conflicto familia-trabajo abarca diversos aspectos, como los roles familiares, las diferencias de género, la educación de los hijos, la adicción al trabajo, etc. En todos ellos, el denominador común es que los roles familiares son incompatibles con las demandas laborales. Por ejemplo, mientras más tiempo se dedica al trabajo, menos tiempo se le dedica a la familia, generando un desequilibrio personal y profesional que se expresa en términos de más estrés, menos o más satisfacción laboral, familiar o marital, según se dé el desbalance entre las responsabilidades familiares y laborales. En ese sentido, se ha encontrado que los varones perciben que la familia es fuente de conflicto con su quehacer en el trabajo, mientras que para las mujeres el trabajo es percibido como fuente de insatisfacción en la familia (Quiroga \& Sánchez, 1997). Precisamente, un tema que entra a tallar en el conflicto familia-trabajo o trabajo-familia es el de los roles asumidos por cada sexo, pues se sabe que mientras el hombre tiene más carga laboral en la mayoría de los casos, la mujer tiene doble carga al asumir roles de madre y esposa en la familia, además de cumplir con las demandas laborales en el trabajo (González, 2011). Al respecto, algunos países de Latinoamérica han comenzado a legislar sobre este tema (Romero \& Kerstenetzky, 2015), sin embargo, a pesar de esta sobrecarga desfavorable para la mujer, diversos estudios reportan que las mujeres tienen niveles más altos de satisfacción laboral que los varones (Gómez, Benítez, Guillén, Gala \& Lupiani, 2000; Arias y Arias, 2014).

En cuanto al bienestar psicológico, se ha visto en un estudio con 228 trabajadores chilenos del sector industrial que el conflicto trabajo-familia se ubica en un nivel intermedio, y que a mayor conflicto menor es el bienestar psicológico. Además, las dimensiones de bienestar psicológico de relaciones positivas y crecimiento personal fueron más altas en las mujeres que en los varones, al igual que el bienestar como puntuación global, pero esta última comparación no fue estadísticamente significativa (Pinto \& Barra, 2015). Una posible explicación al hecho de que las mujeres presenten niveles más altos de satisfacción laboral podría deberse a que, con el paso del tiempo, la mujer ha conquistado nuevos espacios laborales y se siente más autorrealizada porque depende menos de su pareja. Sin embargo, ello no quiere decir que todavía no hayan tensiones en sus familias de origen, como lo ha reportado un estudio cualitativo con mujeres profesionales mexicanas (Castañeda-Rentería, 
2015), por otro lado, un estudio comparó el nivel de satisfacción familiar en mujeres peruanas y españolas de entre 16 y 24 años, y encontró que las primeras están más satisfechas que las segundas (Quezada, Zavala \& Lenti, 2015), lo que también pone en evidencia posibles diferencias culturales a la hora de valorar la satisfacción de la mujer en función de los roles familiares y laborales que asume.

La satisfacción marital también comprende las relaciones de pareja, vale decir que la satisfacción marital es un determinante de la satisfacción familiar porque la formación de la pareja y su vínculo conyugal son los que dan origen a la familia (Ríos, 2005; Arias, 2012a). Existen, en ese sentido, diversos factores que pueden afectar la satisfacción marital, uno de ellos puede ser la semejanza en diversas características psicosociales entre el varón y la mujer. Por ejemplo, varios estudios han puesto de manifiesto que las parejas suelen ser semejantes en su personalidad, nivel de estudios, capacidad intelectual y nivel socioeconómico; y que la satisfacción marital viene condicionada por estas variables. En el estudio de Díaz-Morales, Quiroga, Escribano y Delgado (2009), se encontró, por ejemplo, que la semejanza en inteligencia verbal con sus parejas predecía la satisfacción marital de los varones, mientras que en las mujeres la semejanza en impulsividad predecía mejor la satisfacción marital. En general, las parejas pueden ser simétricas si son semejantes en diversas características tanto psicológicas (personalidad, intereses, etc.) como sociales (nivel socioeconómico, grado de instrucción, etc.), físicas (raza, talla, peso, etc.) o complementarias, pero si no son semejantes se adaptan ambos miembros de la pareja (Villegas \& Mallor, 2012).

La adaptación de la pareja puede deberse a varios aspectos, tales como los criterios de elección de la pareja. En el estudio de Valdez, González-Arratia y Arce López (2007), se encontró que, según los rasgos ideales de sus parejas, los varones se encontraban menos satisfechos que las mujeres con las parejas reales que habían escogido, y con las cuales llevaban una relación estable. Otra variable que afecta la satisfacción marital es el compromiso con la relación, que puede llegar a predecir la estabilidad futura de la pareja (Martínez-Î́nigo, 200o). En el contexto local, un estudio de Murillo (2015) encontró que el nivel de juicio moral era más alto en las personas casadas que en las divorciadas, y según los niveles altos de actitud moral (componente afectivo del juicio moral en el modelo de Lind), podría ser que ante la ocurrencia de conflictos maritales las personas con esta cualidad moral tratan de hacer prevalecer sus puntos de vista, lo cual agrava más el conflicto y explicaría las rupturas en las relaciones matrimoniales. Así, se sabe que varones y mujeres tienen atribuciones de causalidad y responsabilidad diferentes a la hora de explicar el divorcio (Barrón \& Martínez-Íñigo, 1999), debido precisamente a las diferencias psicológicas entre ambos sexos. 
En otro estudio local, que tomó el modelo de Juan Antonio Pérez López, se encontró que las parejas de personas casadas se basaban más en motivos trascendentes a la hora de decidir contraer matrimonio, en comparación con los divorciados que elegían a sus parejas en función de motivos más intrínsecos y extrínsecos (Seperak, 2014). Cabe señalar que este hallazgo es consistente con la teoría de los tipos de amor de Lee (1977), que señala que el estilo de amor ágape o altruista es el que implica el sacrificio por el otro, y que se aproxima a la definición del amor verdadero.

Otros aspectos que se relacionan con la satisfacción marital son la satisfacción sexual (Eguiluz, Calvo \& De la Orta, 2012), la comunicación (Sánchez \& DíazLoving, 2003), el sentido del humor (Zicavo \& Vera, 2011), el perdón (Guzmán-González, Alfaro y Armenta, 2014), la falta de límites claros en función de los diversos roles familiares (Minuchin \& Fishman, 1996) y las experiencias de los varones y las mujeres en sus familias de origen (Quezada, Zavala \& Lenti, 2015). Mientras que entre los factores que mejor predicen la satisfacción marital en términos negativos se tiene a la desconfianza y los celos (Medina, Reyes \& Villar, 2009); entre los factores que mejor la predicen positivamente se tiene a la comunicación mutua (Cuervo, 2013; Platone, 2007).

\section{Satisfacción e integración familiar}

La satisfacción es un estado emocional positivo y placentero que proviene de diversas fuentes, tanto personales como familiares y laborales. La familia, por ejemplo, es una importante fuente de felicidad para los limeños, según los estudios de Alarcón (2002), quien además ha indicado que las personas casadas presentan niveles más elevados de felicidad que las solteras (Alarcón, 2000, 2001, 2009). Sus estudios más recientes también han encontrado que la cohesión familiar se relaciona con la felicidad de manera significativa (Alarcón, 2014), dato que también ha sido corroborado en Arequipa, donde se ha encontrado que la integración familiar se relaciona moderadamente con la felicidad y que la satisfacción personal predice fuertemente la integración familiar (Arias, Masías, Salas, Yépez \& Justo, 2014).

La integración familiar se define aquí como "el grado de salud, equilibrio y armonía de las relaciones que nacen del vínculo conyugal y que naturalmente se orienta a satisfacer la necesidad de trascendencia personal en base al respeto, el diálogo y la comunión entre sus miembros, considerando sus responsabilidades, según el ciclo vital de la familia" (Arias, Castro, Dominguez, Masías, Canales, Castilla \& Castilla, 2013, p. 196). Aun sin detallar, pues la presente investigación se avoca al conflicto familia-trabajo, consideramos importante explicar algunos conceptos sistémicos sobre familia y diferenciar constructos tales como satisfacción familiar e integración familiar, así como otros constructos relacionados: dinámica familiar, interacciones 
familiares, etc. Para ello, comenzaremos señalando que la familia es un sistema en el que sus miembros interactúan según diversos roles y límites que vienen dados por los subsistemas que lo conforman. Es posible reconocer cuatro subsistemas en las familias nucleares: el subsistema conyugal, el subsistema parental, el subsistema fraternal y el subsistema individual (Arias, 2012a). Para comprender las dinámicas familiares, también se debe tener presente el ciclo evolutivo de la familia, que según el paso del tiempo atraviesa por diversas etapas que acarrean crisis propias de cada situación que afrontan los integrantes de la familia. Estas etapas son formación de la pareja, familia con hijos pequeños, familia con hijos adolescentes y familia con hijos adultos. Cada etapa de la familia implica la vivencia y la superación de ciertas crisis que representan oportunidades para que esta se consolide más como sistema (Ríos, 2005).

Por otro lado, las interacciones familiares son todas las formas de comunicación que se establecen entre los miembros de la familia (Dominguez, Aravena, Ramírez \& Yauri, 2013), mientras que las dinámicas familiares tienen que ver con las funciones o los roles que asume cada miembro de la familia, según el subsistema al que pertenece, el ciclo evolutivo en que se encuentra la familia, el espacio y la situación concreta que se trate (Arias, 2012a). Precisamente, las familias se tornan disfuncionales cuando, de acuerdo con todas estas premisas, no es posible satisfacer las necesidades de sus integrantes o se menoscaba el bienestar físico o socioemocional de sus miembros (Villarreal-Zegarra \& Paz, 2015). Puede decirse, entonces, que el grado de satisfacción de los miembros de la familia es un indicador del funcionamiento familiar (Quezada, Zavala \& Lenti, 2015).

De acuerdo con Quiroga y Sánchez (1997), existen cuatro patrones de insatisfacción familiar: el primero denominado mixto, comprende tanto factores familiares como laborales; el segundo factor abarca cuestiones conyugales; el tercer patrón abarca cuestiones domésticas; y el cuarto patrón comprende factores laborales. Las cuestiones conyugales obedecen a temas derivados de la relación de pareja que hemos revisado en el acápite que aborda la satisfacción marital. Los factores domésticos se relacionan con los roles y las responsabilidades familiares y, entre ellos, algunos de los más apremiantes son la crianza y la educación de los hijos.

En ese sentido, el acompañamiento escolar que dan los padres a los hijos es crucial para su óptimo desenvolvimiento académico en la escuela y para su vida académica y profesional futura. Sin embargo, el conflicto con los roles laborales puede afectar negativamente el rendimiento de los hijos en la escuela. Algunos estudios indican, por ejemplo, que mientras más tiempo dedican los padres al trabajo, menor es el logro educativo de sus hijos, y que cada hora de estudio reduce la probabilidad de retraso académico. Además, mientras más alto es el nivel educativo de los padres, 
se reduce en $4 \%$ el atraso escolar, y una hora de acompañamiento de la madre reduce la probabilidad de atraso en $1.6 \%$ (Beltrán, 2013). En un estudio, recientemente publicado, con 730 escolares de nivel primario en Arequipa, encontramos que aquellos que provienen de familias nucleares, extendidas o reconstruidas presentan un nivel más alto de logro académico que los que provienen de familias monoparentales (Arias, Quispe \& Ceballos, 2016).

Los roles domésticos, sin embargo, no solo se relacionan con la educación de los hijos, sino que también abarcan los quehaceres de la casa y el tiempo que comparten los miembros de la familia. En el primer caso, en nuestro medio (como en muchos otros de arraigo hispánico), la mujer tiende a asumir las funciones domésticas de la casa, lo cual le genera una doble carga, que impacta negativamente en su trabajo y su salud (González, 2011). En cuanto al tiempo que tiene la familia para compartirlo en conjunto, son varios los reportes que señalan que en la actualidad las familias ya no pasan la misma cantidad de tiempo juntos y, además, este no es de la misma calidad. En esto, entran a tallar factores tales como la irrupción de las tecnologías dentro del hogar, los horarios de trabajo de los padres, una mirada individualista de las sociedades capitalistas, una cada vez más 'relajada' visión de la familia y el desapego de los hijos durante la adolescencia con la consecuente aparición de conductas disruptivas (Arias, 2013b). Al respecto, no puede olvidarse que los padres, a través de la crianza, transmiten ciertos modelos de conducta a sus hijos (Pacheco, 2003), por tanto, no solo se trata de ocuparse de los quehaceres escolares de los hijos, sino de brindarles el ambiente familiar adecuado para potenciar su madurez socioemocional y el desarrollo de su personalidad. Precisamente, en un estudio con 227 adolescentes de la ciudad de Lima se encontró que aquellos que tienen puntajes más altos en satisfacción familiar tienen también menos expresiones de cólera y hostilidad (Mayorga \& Ñiquen, 2010).

En consecuencia, es necesario dedicarles tiempo a los hijos, como también pasar tiempo en familia. Así, los estudios locales realizados en el ámbito de la familia revelan que de una muestra de 844 familias, en el $62.6 \%$ de ellas la integración familiar es baja, y que esta se relaciona con el nivel socioeconómico, los ingresos mensuales y el grado de instrucción de los padres (Castro, Arias, Dominguez, Masías, Salas, Canales \& Flores, 2013). El nivel socioeconómico, entonces, es una variable importante que predice la satisfacción y la integración familiar, ya que mientras menor sea el nivel socioeconómico menor será la satisfacción familiar (Riesco \& Arela, 2015). Aunque esto podría explicarse por factores netamente económicos, su impacto alcanza también a las interacciones familiares y a diversos aspectos de la dinámica familiar. Por ejemplo, en un estudio con una muestra de escolares limeños se vio que las interacciones familiares registraban diferencias en función del nivel socioeconómico, pues los escolares que provenían de colegios privados se re- 
lacionaban más con la madre, en tanto que los que provenían de escuelas públicas se relacionaban mejor con el padre (Dominguez, Aravena, Ramírez \& Yauri, 2013).

\section{Satisfacción laboral, familia y síndrome de burnout}

En el Perú, el tema de la satisfacción laboral ha sido escasamente abordado. En el ámbito de la capital, podemos señalar los trabajos de Federico León que versan sobre el análisis de los constructos y supuestos teóricos de la teoría bifactorial de Herzberg (León \& Sepúlveda, 1979) y de la teoría instrumental de Vroom (León, 1981). Además, Sonia Palma (1999) creó una prueba que evalúa la satisfacción laboral en los trabajadores limeños. Recientemente, Gamero (2013) ha planteado el abordaje de la satisfacción laboral como una dimensión de la felicidad, para lo cual trabajó con una muestra de 386 personas de la población económicamente activa de Arequipa; así encontró que ambos constructos tienen un $25.91 \%$ de elementos en común, y que la satisfacción laboral contribuye a la felicidad de los trabajadores. De nuestra parte, hemos analizado las diferencias de la satisfacción laboral entre dos grupos de trabajadores de dos tiendas por departamento de la localidad (Arias \& Justo, 2013); además, encontramos que la satisfacción laboral y el clima organizacional se relacionan de manera moderada, y que las dimensiones flexibilidad y reconocimiento del Perfil Organizacional de Likert son las que más se relacionan con la satisfacción laboral (Arias \& Arias, 2014).

Un nuevo estudio sobre satisfacción laboral realizado en Lima hace un análisis psicométrico de la versión breve de la Escala de Satisfacción Laboral de Warr, Cook y Wall, y reporta que las dimensiones de satisfacción laboral intrínseca y extrínseca no discriminan adecuadamente estos constructos (Boluarte \& Soto, 2015). Además de estos trabajos, no se han encontrado investigaciones sobre satisfacción laboral con muestras peruanas. Es decir que el tema de la satisfacción laboral no ha capturado lo suficiente la atención de los investigadores en el área organizacional; menos aún si se trata de su inclusión dentro del campo del conflicto trabajo-familia o familia-trabajo. Sin embargo, una investigadora que ha puesto énfasis en este tema ha sido Belén Salvatierra, que al estudiar el riesgo psicosocial en los mineros peruanos encontró que un aspecto importante en este grupo profesional es el impacto que tienen los conflictos familiares en el trabajo. Estos conflictos están mediados por las condiciones laborales del minero y su perfil sociolaboral, ya que al estar lejos de la familia, tener solvencia económica, tener bajo grado de instrucción y mantener ciertos 'hábitos nocivos' se ve envuelto en una trama de despilfarro, consumo exagerado de alcohol e infidelidad que resquebraja sus relaciones maritales y familiares, y a la larga termina por afectar su rendimiento en el trabajo (Salvatierra, 2001, 2011). 
Otro reporte a considerar en el país sería el estudio de Prado y Del Águila (2010) que aborda más explícitamente el ajuste y la satisfacción de las parejas que trabajan. Estos autores han encontrado que la satisfacción afectiva predice el ajuste diádico de la pareja, en el caso de los varones, y el factor intelectual, en el caso de las mujeres. Después de estos trabajos, podemos mencionar un breve estudio que realizamos en una muestra pequeña de 20 trabajadores, en quienes evaluamos el síndrome de burnout, la satisfacción laboral y la integración familiar en trabajadores de una tienda por departamento en Arequipa; y se encontró que la integración familiar tenía un efecto amortiguador en la satisfacción laboral cuando los niveles de estrés son elevados (Arias y Ceballos, 2016). Estos datos, sin embargo, no son concluyentes por el tamaño de la muestra y el tipo de muestreo, por lo que no podríamos generalizar los hallazgos a otras empresas.

No obstante, sabemos que el conflicto familia-trabajo puede afectar la salud del trabajador y expresarse en bajos niveles de satisfacción laboral y altos niveles de estrés (Sanz, 2011). El estrés es un estado de tensión psicofisiológica que responde a diversas causas (Selye, 1960). Cuando el estrés se relaciona con factores o contextos laborales, se habla de estrés laboral (Atalaya, 2001). Con muestras de la ciudad de Arequipa, hemos podido encontrar que el estrés laboral se relaciona moderadamente con el consumo de sustancias psicoactivas como el alcohol (Arias, 2012b) y que los estresores más recurrentes son los usos inadecuados del tiempo para dormir y para alimentarse (Arias, 2012c). Entre las causas más comunes de estrés laboral se tiene el escaso control, la sobrecarga laboral, la poca claridad en los roles y las funciones, la limitada comunicación, las pobres condiciones de trabajo, el escaso apoyo, la inseguridad laboral, las altas demandas laborales, el uso de tecnología, la cultura y el clima organizacional, y los problemas familiares y personales (Latha \& Janaki, 2012). Cuando las condiciones que generan el estrés tienen lugar de manera crónica, se habla de estrés crónico laboral, y una de las consecuencias del estrés crónico en el trabajo es el síndrome de burnout (Arias \& Jiménez, 2012b), que tiene efectos negativos en la salud física y mental de los trabajadores (Boada, De Diego \& Agulló, 2004).

El síndrome de burnout se caracteriza por la presencia de la triada de síntomas que comprende el agotamiento emocional, la despersonalización y la baja realización personal, según el modelo de Cristina Maslach y Susan Jackson (1981). Asimismo, existen diversos modelos que explican el síndrome de burnout; algunos ponen énfasis en las características demográficas y psicológicas de los trabajadores, otros ponen énfasis en las condiciones de trabajo, y otros ponen énfasis en las relaciones que se establecen entre los trabajadores y los destinatarios de sus servicios (Gil-Monte \& Peiró, 1999). En ese sentido, las primeras teorías del síndrome de burnout hipotetizaban que este se daba en profesiones de servicios humanos, en las que los trabajadores se relacionan con otras personas, que dependen de ellos; el 
desequilibrio de estas relaciones y la responsabilidad de los trabajadores para con los usuarios de su trabajo era lo que explicaba la aparición del síndrome. Por esta razón, los grupos profesionales, en los que se comenzó a investigar este síndrome, fueron el personal de salud, los profesores y los policías (Arias \& Jiménez, 2012a). Sin embargo, con el tiempo, se ha visto que este síndrome se da en cualquier grupo profesional y que los factores que mejor explican sus manifestaciones son los elementos estructurales y organizacionales del trabajo (Arias, 2015).

Asimismo, en Arequipa, hemos investigado la prevalencia de este síndrome y sus relaciones con múltiples variables, como la espiritualidad en el trabajo (Arias, Riveros \& Salas, 2012), el clima organizacional (Arias \& Zegarra, 2013), la felicidad (Arias, Masías y Justo, 2014) y los estilos de afrontamiento (Arias, Justo \& Muñoz, 2014). Como conclusión, tenemos que un clima organizacional óptimo, la espiritualidad y la felicidad se relacionan negativamente con el síndrome de burnout. Asimismo, los estilos de afrontamiento evitativo y pasivo se relacionan positivamente entre sí, pero negativamente con el estilo de afrontamiento activo (Arias, 2015).

Por otro lado, se sabe que diversas variables, como la autoeficacia (Rubio, Osca, Recio, Urien \& Peiró, 2015) y el involucramiento (López-Araújo, Osca \& Peiró, 2007) han sido considerados como importantes moduladores de la satisfacción laboral y el estrés, dentro del marco del conflicto trabajo-familia. También se ha visto que el apoyo familiar que se da al trabajador en el centro laboral reduce ostensiblemente las manifestaciones de estrés laboral y de síndrome de burnout (Martínez-Pérez \& Osca, 2002). Por ello, se han venido desarrollando diversos mecanismos, prácticas y políticas laborales para revertir los efectos negativos del conflicto trabajo-familia, que favorezcan la recuperación de las personas que padecen el estrés ocasionado por estas situaciones (Sanz, 2011). Dentro de estas prácticas, se tienen servicios y apoyo adecuados a las exigencias familiares, como permisos parentales, cunas empresariales, servicios de guardería en el trabajo, lactarios para las madres puérperas y talleres de capacitación para los trabajadores que son padres de familia. También se han implementado modelos balanceados de trabajo para padres y madres con exigencias familiares particulares, tales como horarios flexibles, trabajo de medio tiempo, trabajo de pareja, flexibilidad en la entrada y la salida, teletrabajo, trabajo intermitente, etc. (Donati, 2015).

Es importante considerar que en la universidad donde se efectúa el estudio se implementan diversas prácticas de responsabilidad familiar empresarial, pero estas son más accesibles a los trabajadores administrativos y a los profesores de tiempo completo. El presente estudio aborda el conflicto familia-trabajo en varios niveles de investigación: descriptivo, comparativo, correlacional y predictivo; se trata, por 
tanto, de una investigación cuantitativa no experimental. Tan es así que sobre la base de diversas investigaciones que analizan las variables de estudio por separado, se plantea valorar la relación entre diversas variables, como la satisfacción marital, la satisfacción familiar, la integración familiar, la satisfacción laboral y el síndrome de burnout.

Además de ello, se pretende valorar cuál de las variables familiares (satisfacción marital, satisfacción familiar, integración familiar) predice mejor la satisfacción laboral y el síndrome de burnout. En virtud de ello, pretendemos dar respuesta a las siguientes preguntas de investigación: 1) ¿Qué diferencias existen entre la satisfacción marital, la satisfacción familiar, la integración familiar, la satisfacción laboral y el síndrome de burnout en los trabajadores de una universidad privada de Arequipa, en función del sexo, el cargo, el tiempo de servicio y los ingresos mensuales? 2) ¿Qué relaciones se pueden encontrar entre la satisfacción marital, la satisfacción familiar, la integración familiar, la satisfacción laboral y el síndrome de burnout en los trabajadores de una universidad privada de Arequipa? 3) ¿Cuál es el impacto que tiene la familia en la satisfacción laboral y el estrés laboral de los trabajadores de esta institución?

\section{Método}

\section{Muestra}

La muestra está constituida por 213 trabajadores de una universidad privada en Arequipa, de los cuales, $43.6 \%$ son varones y $56.4 \%$ son mujeres, $38.9 \%$ son administrativos y $61.1 \%$ son profesores. La edad promedio fue de 30.35, con una desviación estándar de $\pm 9 \cdot 35$. Se tomó como criterio de inclusión el que todos los trabajadores tuvieran una relación de pareja estable, sea que fueran casados o convivientes. El $30.51 \%$ tenía menos de cinco años de tiempo de servicio, el 60.9\% tenía entre cinco y diez años de trabajo en la universidad, y el 8.3\% tenía más de diez años de tiempo de servicio. El $2.8 \%$ ganaba el sueldo mínimo; el 6o \%, entre el mínimo y 2500 soles; y el $38 \%$, más de 2500 soles.

\section{Instrumentos}

Ficha de datos personales. Para los fines de la investigación se aplicó una ficha de datos sociodemográficos que contenía información sobre la edad, el sexo, los ingresos mensuales, el cargo y el tiempo de servicio.

Escala de Satisfacción Marital de Pick y Andrade. Esta escala fue propuesta por S. Pick y P. Andrade en 1988 para valorar la satisfacción marital. Consta de 24 ítems, 
distribuidos en tres dominios o dimensiones: la satisfacción con la interacción conyugal (ítems 1-10), la satisfacción con los aspectos emocionales del cónyuge (ítems 11-15) y la dimensión satisfacción con los aspectos organizacionales y estructurales de la relación (ítems 16-24). Todas las alternativas de respuesta se puntúan del uno al tres, en función de las siguientes afirmaciones: me gustaría muy diferente, me gustaría algo diferente y me gustaría como está pasando. La escala cuenta con un mínimo de 24 puntos y un máximo de 72 . La consistencia interna de la prueba fue obtenida mediante el índice alfa de Cronbach, con valores superiores a o.8o.

Escala de Satisfacción Familiar de Olson y Wilson. El instrumento contiene dos subescalas, de cohesión y adaptabilidad, utilizadas para evaluar el modelo circumplejo. Se compone de 14 ítems. Los ítems impares valoran la cohesión y los pares, la adaptabilidad. La validez de esta prueba está respaldada por las correlaciones ítem-test que superan el índice de correlación o.40. Además, cuenta con un índice de confiabilidad de $\mathrm{a}=0.90$, mediante el método de consistencia interna y la prueba de Cronbach.

Inventario de Integración Familiar. Este instrumento fue construido y validado por Arias, Castro, Dominguez, Masías, Canales, Castilla y Castilla (2013), y consta de 52 ítems dispuestos en una escala tipo Likert que va de siempre (5) a nunca (1), que se aplica a personas jefes de familia, varones o mujeres, que tengan hijos. La prueba cuenta con criterios de validez de contenido, criterio y constructo; además, posee un índice de confiabilidad por el método alfa de Cronbach de o.739. Asimismo, cuenta con baremos en tres rangos de interpretación: bajo, moderado y alto.

Escala de Satisfacción en el Trabajo de Warr, Cook y Wall. La Escala de Satisfacción en el Trabajo tiene 15 ítems distribuidos en dos dimensiones de satisfacción laboral: factores intrínsecos (compuesta por los ítems pares) y factores extrínsecos (compuesta por los ítems impares). Cuenta, además, con siete niveles de respuesta en una escala de Likert que abarca las siguientes afirmaciones: muy insatisfecho, insatisfecho, moderadamente insatisfecho, ni insatisfecho ni satisfecho, moderadamente satisfecho, satisfecho y muy satisfecho. Cuenta con un índice de confiabilidad test-retest de 0.79 .

Inventario de Burnout de Maslach. Este instrumento fue validado por Gil-Monte y Peiró (1999b) en una muestra multiocupacional de Colombia y consta de 22 ítems en una escala tipo Likert que comprende respuestas desde 'todos los días' hasta 'nunca', con una valoración de 6 a o. El inventario se compone de las dimensiones de agotamiento emocional, despersonalización y baja realización personal. Para efectos de nuestro estudio, determinamos el índice de consistencia interna a través de la prueba Alpha de Cronbach, y se obtuvo un valor de $a=0.717$, lo que sugiere que brinda resultados confiables. 


\section{Procedimiento}

En primer lugar, se procedió a solicitar los permisos correspondientes a los directivos de la universidad, en el área de Desarrollo Humano. Una vez que se obtuvieron las autorizaciones, se procedió a recoger los datos de la investigación, para lo cual se aplicaron los instrumentos dentro del horario de trabajo y en los puestos donde realizan sus labores cotidianas. Para el caso de los trabajadores que no tenían un puesto fijo, como una oficina o un cubículo, se utilizaron las salas de reuniones y la sala de profesores para evaluar a los docentes o al personal administrativo. Los datos se recogieron entre los meses de septiembre de 2015 y febrero de 2016.

\section{Resultados}

En la Tabla 1, se aprecian los estadísticos descriptivos del estudio, en los que la satisfacción marital y la satisfacción familiar registran una media moderada, mientras que la integración familiar es baja. La satisfacción laboral intrínseca es moderada alta y la satisfacción laboral extrínseca es alta, mientras que la satisfacción laboral es alta. En cuanto a las medidas del síndrome de burnout, el agotamiento emocional es leve, la despersonalización es moderada y la baja realización personal es severa, mientras que el síndrome de burnout es moderado. Las desviaciones estándar son altas en la mayoría de los casos, lo cual indica que hay variabilidad en los datos, excepto en la variable satisfacción laboral.

Tabla 1.

Estadísticos descriptivos de las variables de estudio

\begin{tabular}{|lrrrrrrrrrr|}
\hline & $\begin{array}{c}\text { Satisf. } \\
\text { marital }\end{array}$ & $\begin{array}{c}\text { Satisf. } \\
\text { familiar }\end{array}$ & $\begin{array}{c}\text { Integ. } \\
\text { familiar }\end{array}$ & $\begin{array}{c}\text { Satisf. } \\
\text { intrín- } \\
\text { seca }\end{array}$ & $\begin{array}{c}\text { Satisf. } \\
\text { extrín- } \\
\text { seca }\end{array}$ & $\begin{array}{c}\text { Satisf. } \\
\text { laboral }\end{array}$ & Agot. & Despers. & $\begin{array}{c}\text { Baja } \\
\text { realiz. }\end{array}$ & Burnout \\
\hline Media & 30.807 & 45.145 & 136.779 & 35.389 & 39.906 & 77.201 & 19.042 & 7.784 & 32.647 & 59.516 \\
Mediana & 33.000 & 50.000 & 155.000 & 38.000 & 42.000 & 82.000 & 19.000 & 6.000 & 34.000 & 58.000 \\
Moda & 30.000 & 44.000 & 135.000 & 41.000 & 48.000 & 87.000 & 18.000 & 7.000 & 48.000 & 52.000 \\
Desv. típ. & 20.168 & 19.504 & 62.102 & 9.776 & 10.914 & 19.915 & 11.062 & 6.695 & 11.400 & 17.974 \\
Varianza & 406.751 & 380.436 & 3856.711 & 95.588 & 119.123 & 396.634 & 122.390 & 44.830 & 129.974 & 323.100 \\
Asimetría & -.182 & -1.438 & -1.392 & -1.789 & -1.696 & -2.124 & .874 & .956 & -.373 & 1.048 \\
Curtosis & -.670 & 1.122 & .713 & 3.954 & 4.060 & 5.748 & 1.722 & 1.022 & -.434 & 5.868 \\
\hline
\end{tabular}

En la Tabla 2, se observan las correlaciones entre las variables. La edad no se relaciona con ninguna de ellas. La satisfacción marital solo tiene relaciones positivas 
moderadas con la satisfacción familiar $(\mathrm{r}=.451)$ y la integración familiar $(\mathrm{r}=.541)$; la satisfacción familiar, en cambio, se relaciona moderada y positivamente con la integración familiar $(\mathrm{r}=.417)$, pero baja y positivamente con la satisfacción laboral y la satisfacción laboral extrínseca. La satisfacción laboral intrínseca se relaciona de manera alta y positiva con la satisfacción laboral extrínseca y la satisfacción laboral. El agotamiento emocional se relaciona de manera fuerte y positiva con la despersonalización $(\mathrm{r}=.605)$ y con el síndrome de burnout $(\mathrm{r}=.775)$, la despersonalización se relaciona de manera baja y negativa con la baja realización personal, y de manera positiva moderada con el síndrome de burnout; mientras que la baja realización personal también se relaciona moderada y positivamente con el síndrome.

\section{Tabla 2.}

\section{Correlaciones efectuadas entre las variables de estudio}

\begin{tabular}{|c|c|c|c|c|c|c|c|c|c|c|c|}
\hline & Edad & $\begin{array}{l}\text { Satisf. } \\
\text { marital }\end{array}$ & $\begin{array}{l}\text { Satisf. } \\
\text { familia }\end{array}$ & $\begin{array}{l}\text { Integ. } \\
\text { familia }\end{array}$ & $\begin{array}{l}\text { Satisf. } \\
\text { intríns. }\end{array}$ & $\begin{array}{l}\text { Satisf. } \\
\text { extríns. }\end{array}$ & $\begin{array}{l}\text { Satisf. } \\
\text { laboral }\end{array}$ & Agotam. & Despers. & $\begin{array}{c}\text { Baja } \\
\text { realiz. }\end{array}$ & Burnout \\
\hline Edad & 1 & .168 & -.033 & .123 & -.090 & -.070 & -.071 & .002 & -.024 & .128 & .082 \\
\hline $\begin{array}{l}\text { Satisf. } \\
\text { marital }\end{array}$ & & 1 & $\left..4511^{*}\right)$ & $\left..541^{(*}\right)$ & .128 & .152 & .162 & .018 & -.081 & -.163 & -.120 \\
\hline $\begin{array}{l}\text { Satisf. } \\
\text { familiar }\end{array}$ & & & 1 & $.417\left(^{*}\right)$ & .198 & $.224\left(^{*}\right)$ & $.245\left(^{*}\right)$ & -.115 & -.140 & -.109 & -.185 \\
\hline $\begin{array}{l}\text { Integ. } \\
\text { familiar }\end{array}$ & & & & 1 & -.046 & -.035 & -.030 & .065 & -.020 & -.059 & -.008 \\
\hline $\begin{array}{l}\text { Satisf. } \\
\text { intríns. }\end{array}$ & & & & & 1 & $.902\left(^{*}\right)$ & $.959\left(^{(*}\right)$ & -.151 & -.081 & -.009 & -.132 \\
\hline $\begin{array}{l}\text { Satisf. } \\
\text { extríns. }\end{array}$ & & & & & & 1 & $\left..9411^{*}\right)$ & -.188 & -.123 & -.010 & -.173 \\
\hline $\begin{array}{l}\text { Satisf. } \\
\text { laboral }\end{array}$ & & & & & & & 1 & -.161 & -.108 & -.010 & -.150 \\
\hline Agotam. & & & & & & & & 1 & $.605\left(^{*}\right)$ & -.080 & $.775\left(^{*}\right)$ \\
\hline Despers. & & & & & & & & & 1 & $\left.-.219^{*}\right)$ & $.592\left(^{*}\right)$ \\
\hline $\begin{array}{l}\text { Baja } \\
\text { realiz. }\end{array}$ & & & & & & & & & & 1 & $.496\left(^{*}\right)$ \\
\hline Burnout & & & & & & & & & & & 1 \\
\hline
\end{tabular}

${ }^{*} \mathrm{p}<0.01$

También se hicieron comparaciones entre las variables tomando como criterios el sexo, el cargo, el tiempo de servicio y los ingresos económicos. En la Tabla 3, por ejemplo, se tienen las comparaciones de la satisfacción marital, la satisfacción familiar, la integración familiar, la satisfacción intrínseca, la satisfacción extrínseca, la satisfacción laboral, el agotamiento emocional, la despersonalización, la baja realiza- 
ción personal y el síndrome de burnout, según el sexo de los trabajadores. Se utilizó la prueba paramétrica t de Student, por tratarse de valores cuantitativos con dos niveles de comparación (varón y mujer). Se puede ver que la satisfacción marital registra diferencias significativas entre varones y mujeres $(\mathrm{p}<0.018)$, a favor de los primeros, es decir, los varones se sienten más satisfechos con sus parejas que las féminas. La integración familiar también registró diferencias significativas $(\mathrm{p}<0.05)$ a favor de los varones. El síndrome de burnout también registró diferencias significativas a favor de las mujeres $(\mathrm{p}<0.026)$. Esto quiere decir que los varones tienen mayor satisfacción marital y mayor integración familiar en sus hogares, pero son las mujeres quienes tienen niveles más altos del síndrome de burnout, en comparación con los varones.

Tabla 3.

\section{Comparaciones por sexo}

\begin{tabular}{|c|c|c|c|c|c|c|}
\hline & Sexo & $\mathrm{N}$ & Media & $\begin{array}{c}\text { Des- } \\
\text { viación } \\
\text { típica }\end{array}$ & $\mathrm{t}$ & $\mathrm{p}$ \\
\hline \multirow{2}{*}{ Satisfacción marital } & Varón & 93 & 34.129 & $19 \cdot 508$ & 2.383 & 0.018 \\
\hline & Mujer & 120 & 26.821 & 21.118 & & \\
\hline \multirow{2}{*}{ Satisfacción familiar } & Varón & 93 & 44.817 & 19.813 & -0.600 & 0.548 \\
\hline & Mujer & 120 & 46.607 & $19 \cdot 776$ & & \\
\hline \multirow{2}{*}{ Integración familiar } & Varón & 93 & 147.086 & 54.091 & 1.969 & 0.050 \\
\hline & Mujer & 120 & 128.714 & 68.305 & & \\
\hline \multirow{2}{*}{ Satisfacción intrínseca } & Varón & 93 & 34.645 & 10.408 & -0.552 & 0.581 \\
\hline & Mujer & 120 & $35 \cdot 500$ & 10.144 & & \\
\hline \multirow{2}{*}{ Satisfacción extrínseca } & Varón & 93 & 39.118 & 11.638 & -0.663 & 0.508 \\
\hline & Mujer & 120 & 40.261 & 11.294 & & \\
\hline \multirow{2}{*}{ Satisfacción laboral } & Varón & 93 & 76.075 & 21.162 & -0.442 & 0.658 \\
\hline & Mujer & 120 & $77 \cdot 476$ & 20.899 & & \\
\hline \multirow{2}{*}{ Agotamiento } & Varón & 93 & 18.086 & 11.099 & -1.297 & 0.196 \\
\hline & Mujer & 120 & 20.333 & 11.857 & & \\
\hline \multirow{2}{*}{ Despersonalización } & Varón & 93 & 7.172 & 6.683 & -1.132 & 0.258 \\
\hline & Mujer & 120 & 8.357 & 7.183 & & \\
\hline \multirow{2}{*}{ Baja realización } & Varón & 93 & 32.290 & 11.389 & -1.514 & 0.131 \\
\hline & Mujer & 120 & 34.797 & 10.629 & & \\
\hline \multirow{2}{*}{ Burnout } & Varón & 93 & 57.623 & 17.793 & -2.244 & 0.026 \\
\hline & Mujer & 120 & 63.642 & 17.840 & & \\
\hline
\end{tabular}


En la Tabla 4, se muestran los valores de las medias comparadas según el cargo de los trabajadores de la universidad (administrativos y docentes). Se puede ver que la satisfacción marital es mayor en los docentes que en los administrativos, con niveles de significancia altos $(\mathrm{p}<0.006)$. Asimismo, los administrativos tienen niveles más altos de baja realización personal $(\mathrm{p}<0.000)$ y del síndrome de burnout $(\mathrm{p}<0.003)$.

\section{Tabla 4 . \\ Comparaciones por cargo}

\begin{tabular}{|c|c|c|c|c|c|c|}
\hline & Cargo & $\mathrm{N}$ & Media & $\begin{array}{l}\text { Des- } \\
\text { viación } \\
\text { típica }\end{array}$ & $\mathrm{t}$ & $\mathrm{p}$ \\
\hline \multirow{2}{*}{ Satisfacción marital } & Administrativos & 83 & 25.831 & 22.367 & -2.793 & 0.006 \\
\hline & Docentes & 130 & 33.984 & 18.009 & & \\
\hline \multirow{2}{*}{ Satisfacción familiar } & Administrativos & 83 & 42.578 & 21.823 & -1.472 & 0.143 \\
\hline & Docentes & 130 & 46.784 & 17.763 & & \\
\hline \multirow{2}{*}{ Integración familiar } & Administrativos & 83 & 127.192 & 63.281 & -1.794 & 0.075 \\
\hline & Docentes & 130 & 142.900 & 60.792 & & \\
\hline \multirow{2}{*}{ Satisfacción intrínseca } & Administrativos & 83 & 34.192 & 12.456 & -1.291 & 0.199 \\
\hline & Docentes & 130 & 36.153 & $7 \cdot 546$ & & \\
\hline \multirow{2}{*}{ Satisfacción extrínseca } & Administrativos & 83 & 39.192 & 14.074 & -0.684 & 0.495 \\
\hline & Docentes & 130 & 40.361 & 8.325 & & \\
\hline \multirow{2}{*}{ Satisfacción laboral } & Administrativos & 83 & 75.26 & 26.405 & -1.005 & 0.317 \\
\hline & Docentes & 130 & 78.438 & $14 \cdot 306$ & & \\
\hline \multirow{2}{*}{ Agotamiento } & Administrativos & 83 & 18.180 & 13.056 & -0.849 & 0.397 \\
\hline & Docentes & 130 & 19.592 & $9 \cdot 591$ & & \\
\hline \multirow{2}{*}{ Despersonalización } & Administrativos & 83 & 8.072 & $7 \cdot 559$ & 0.478 & 0.633 \\
\hline & Docentes & 130 & 7.600 & 6.104 & & \\
\hline \multirow{2}{*}{ Baja realización } & Administrativos & 83 & 38.024 & 9.064 & 6.234 & 0.000 \\
\hline & Docentes & 130 & 29.215 & 11.441 & & \\
\hline \multirow{2}{*}{ Burnout } & Administrativos & 83 & 64.313 & 19.861 & 3.031 & 0.003 \\
\hline & Docentes & 130 & 56.453 & 15.999 & & \\
\hline
\end{tabular}

En la Tabla 5, se tiene el análisis de varianza que compara los puntajes obtenidos en las variables de estudio, según el tiempo de servicio. Se puede ver que se registran diferencias significativas en agotamiento emocional $(\mathrm{p}<0.021)$, despersonalización ( $\mathrm{p}$ $<0.001$ ) y baja realización personal $(\mathrm{p}<\mathrm{0.013}$ ). Ello quiere decir que quienes tienen más tiempo de servicio presentan más manifestaciones del síndrome de burnout. 
Tabla 5.

Análisis de varianza según el tiempo de servicio

\begin{tabular}{|c|c|c|c|c|c|c|}
\hline & & $\begin{array}{l}\text { Suma de } \\
\text { cuadrados }\end{array}$ & $\mathrm{gl}$ & $\begin{array}{c}\text { Media } \\
\text { cuadrática }\end{array}$ & $\mathrm{F}$ & Sig. \\
\hline \multirow{3}{*}{ Satisfacción marital } & Intergrupos & 1542.098 & 4 & $385 \cdot 525$ & .947 & 0.438 \\
\hline & Intragrupos & 84689.010 & 208 & 407.159 & & \\
\hline & Total & 86231.108 & 212 & & & \\
\hline \multirow{3}{*}{ Satisfacción familiar } & Intergrupos & 532.341 & 4 & 133.085 & .346 & 0.847 \\
\hline & Intragrupos & 80120.147 & 208 & 385.193 & & \\
\hline & Total & 80652.488 & 212 & & & \\
\hline \multirow{3}{*}{ Integración familiar } & Intergrupos & $13035 \cdot 974$ & 4 & 3258.994 & .843 & 0.500 \\
\hline & Intragrupos & 804586.655 & 208 & 3868.205 & & \\
\hline & Total & 817622.629 & 212 & & & \\
\hline \multirow{3}{*}{$\begin{array}{l}\text { Satisfacción } \\
\text { intrínseca }\end{array}$} & Intergrupos & 168.041 & 4 & 42.010 & .435 & 0.783 \\
\hline & Intragrupos & 20096.616 & 208 & 96.618 & & \\
\hline & Total & 20264.657 & 212 & & & \\
\hline \multirow{3}{*}{$\begin{array}{l}\text { Satisfacción } \\
\text { extrínseca }\end{array}$} & Intergrupos & 361.686 & 4 & 90.422 & .756 & 0.555 \\
\hline & Intragrupos & 24892.436 & 208 & 119.675 & & \\
\hline & Total & 25254.122 & 212 & & & \\
\hline \multirow{3}{*}{ Satisfacción laboral } & Intergrupos & 740.967 & 4 & 185.242 & .462 & 0.763 \\
\hline & Intragrupos & $83345 \cdot 352$ & 208 & 400.699 & & \\
\hline & Total & 84086.319 & 212 & & & \\
\hline \multirow{3}{*}{ Agotamiento } & Intergrupos & 1401.725 & 4 & 350.431 & 2.970 & 0.021 \\
\hline & Intragrupos & 24544.894 & 208 & 118.004 & & \\
\hline & Total & 25946.620 & 212 & & & \\
\hline \multirow{3}{*}{ Despersonalización } & Intergrupos & 807.299 & 4 & 201.825 & 4.827 & 0.001 \\
\hline & Intragrupos & 8696.767 & 208 & 41.811 & & \\
\hline & Total & 9504.066 & 212 & & & \\
\hline \multirow{3}{*}{ Baja realización } & Intergrupos & 1610.483 & 4 & 402.621 & 3.228 & 0.013 \\
\hline & Intragrupos & 25944.109 & 208 & $124 \cdot 731$ & & \\
\hline & Total & 27554.592 & 212 & & & \\
\hline
\end{tabular}




\begin{tabular}{|llrrrrr|}
\hline & Intergrupos & 1816.565 & 4 & 454.141 & 1.417 & 0.230 \\
Burnout & Intragrupos & 66680.627 & 208 & 320.580 & & \\
& Total & 68497.192 & 212 & & & \\
\hline
\end{tabular}

En la Tabla 6, se comparan las diversas variables de estudio en función de los ingresos mensuales, a través del análisis de varianza. Las diferencias que se registran de manera significativa comprenden la satisfacción laboral intrínseca y extrínseca, la satisfacción laboral como puntaje total, el agotamiento emocional, la despersonalización y la baja realización personal. Ello quiere decir que las diferencias en términos económicos solo tocan a las variables laborales y no a las familiares; así, los más perjudicados son quienes perciben menos ingresos mensuales.

Tabla 6.

Análisis de varianza según los ingresos mensuales

\begin{tabular}{|c|c|c|c|c|c|c|}
\hline & & $\begin{array}{l}\text { Suma de } \\
\text { cuadrados }\end{array}$ & gl & $\begin{array}{c}\text { Media } \\
\text { cuadrática }\end{array}$ & $\mathrm{F}$ & Sig. \\
\hline \multirow{3}{*}{ Satisfacción marital } & Intergrupos & $435 \cdot 311$ & 2 & 217.656 & .533 & 0.588 \\
\hline & Intragrupos & 85795.797 & 210 & 408.551 & & \\
\hline & Total & 86231.108 & 212 & & & \\
\hline \multirow{3}{*}{ Satisfacción familiar } & Intergrupos & 147.875 & 2 & 73.938 & .193 & 0.825 \\
\hline & Intragrupos & 80504.613 & 210 & 383.355 & & \\
\hline & Total & 80652.488 & 212 & & & \\
\hline \multirow{3}{*}{ Integración familiar } & Intergrupos & 3786.285 & 2 & 1893.142 & .489 & 0.614 \\
\hline & Intragrupos & 813836.345 & 210 & 3875.411 & & \\
\hline & Total & 817622.629 & 212 & & & \\
\hline \multirow{3}{*}{ Satisfacción intrínseca } & Intergrupos & 776.863 & 2 & 388.432 & 4.186 & 0.016 \\
\hline & Intragrupos & 19487.794 & 210 & 92.799 & & \\
\hline & Total & 20264.657 & 212 & & & \\
\hline \multirow{3}{*}{ Satisfacción extrínseca } & Intergrupos & $1053 \cdot 978$ & 2 & 526.989 & 4.573 & 0.011 \\
\hline & Intragrupos & 24200.144 & 210 & 115.239 & & \\
\hline & Total & 25254.122 & 212 & & & \\
\hline
\end{tabular}




\begin{tabular}{|c|c|c|c|c|c|c|}
\hline \multirow{3}{*}{ Satisfacción laboral } & Intergrupos & 2383.523 & 2 & 1191.762 & 3.063 & 0.049 \\
\hline & Intragrupos & 81702.796 & 210 & 389.061 & & \\
\hline & Total & 84086.319 & 212 & & & \\
\hline \multirow{3}{*}{ Agotamiento } & Intergrupos & 1120.250 & 2 & 560.125 & 4.738 & 0.010 \\
\hline & Intragrupos & 24826.370 & 210 & 118.221 & & \\
\hline & Total & 25946.620 & 212 & & & \\
\hline \multirow{3}{*}{ Despersonalización } & Intergrupos & 778.917 & 2 & 389.458 & $9 \cdot 374$ & o.ooo \\
\hline & Intragrupos & 8725.149 & 210 & 41.548 & & \\
\hline & Total & 9504.066 & 212 & & & \\
\hline \multirow{3}{*}{ Baja realización } & Intergrupos & 1135.378 & 2 & 567.689 & $4 \cdot 512$ & 0.012 \\
\hline & Intragrupos & 26419.213 & 210 & 125.806 & & \\
\hline & Total & 27554.592 & 212 & & & \\
\hline \multirow{3}{*}{ Burnout } & Intergrupos & 758.910 & 2 & 379.455 & 1.176 & 0.310 \\
\hline & Intragrupos & 67738.283 & 210 & 322.563 & & \\
\hline & Total & 68497.192 & 212 & & & \\
\hline
\end{tabular}

Luego del procesamiento a nivel descriptivo, correlacional y comparativo, se hizo el procesamiento predictivo a través del análisis de regresión lineal. Se valoró primero si la edad, la satisfacción marital, la satisfacción familiar, la integración familiar, el agotamiento emocional, la despersonalización, la baja realización personal y el síndrome de burnout tienen algún poder predictivo sobre la satisfacción laboral. Los datos de este primer modelo se muestran en la Tabla 7 , en la que se puede ver que el nivel de significancia es alto $(\mathrm{p}<0.000)$.

\section{Tabla 7 . \\ Resumen del modelo 1}

\begin{tabular}{|c|c|c|c|c|c|c|c|c|}
\hline \multirow[b]{2}{*}{$\mathrm{R}$} & \multirow[b]{2}{*}{ R cuadrado } & \multirow{2}{*}{$\begin{array}{c}\text { R cuadrado } \\
\text { corregida }\end{array}$} & \multirow{2}{*}{$\begin{array}{l}\text { Error típ. de } \\
\text { la estimación }\end{array}$} & \multicolumn{5}{|c|}{ Estadísticos de cambio } \\
\hline & & & & $\begin{array}{c}\text { Cambio en R } \\
\text { cuadrado }\end{array}$ & $\begin{array}{c}\text { Cambio } \\
\text { en F }\end{array}$ & gl1 & gl2 & $\begin{array}{c}\text { Sig. cambio } \\
\text { en F }\end{array}$ \\
\hline 0.358 & 0.128 & 0.094 & 18.955 & 0.128 & 3.754 & 8 & 204 & 0.000 \\
\hline
\end{tabular}

Variables predictoras: Edad, satisfacción marital, satisfacción familiar, integración familiar, agotamiento emocional, despersonalización, baja realización personal, síndrome de burnout.

Variable dependiente: Satisfacción laboral. 
Asimismo, el análisis de varianza de este primer modelo se observa en la Tabla 8, donde se aprecia que las diferencias halladas son significativas.

Tabla 8.

\section{Análisis de varianza del modelo 1}

\begin{tabular}{|cccccc|}
\hline Modelo & $\begin{array}{c}\text { Suma de } \\
\text { cuadrados }\end{array}$ & gl & Media cuadrática & F & Sig. \\
\hline Regresión & 10790.019 & 8 & 1348.752 & 3.754 & 0.0oo \\
Residual & 73296.301 & 204 & 359.296 & & \\
Total & 84086.319 & 212 & & & \\
\hline
\end{tabular}

En la Tabla 9, se tienen los coeficientes betas estandarizados. Aquí se aprecia que la satisfacción marital, la satisfacción familiar y la integración familiar alcanzan valores significativos; lo que supone que predicen la satisfacción laboral, sin embargo, tanto la satisfacción marital como la familiar predicen positivamente la satisfacción laboral, pero la integración familiar la predice en sentido negativo. Esto quiere decir que a más satisfacción marital y familiar, habrá también mayor satisfacción laboral, pero a mayor integración familiar, habría menos satisfacción laboral.

Tabla 9.

Coeficientes betas estandarizados de las variables predictoras del modelo 1

\begin{tabular}{|c|c|c|c|c|c|c|c|c|c|c|}
\hline \multirow{2}{*}{ Modelo 1} & \multicolumn{2}{|c|}{$\begin{array}{l}\text { Coeficientes no } \\
\text { estandarizados }\end{array}$} & \multirow{2}{*}{$\begin{array}{c}\begin{array}{c}\text { Coeficientes } \\
\text { estandari- } \\
\text { zados }\end{array} \\
\text { Beta }\end{array}$} & \multirow{2}{*}{$\mathrm{t}$} & \multirow{2}{*}{ Sig. } & \multicolumn{3}{|c|}{ Correlaciones } & \multicolumn{2}{|c|}{$\begin{array}{l}\text { Estadísticos de } \\
\text { colinealidad }\end{array}$} \\
\hline & B & $\begin{array}{l}\text { Error } \\
\text { típico }\end{array}$ & & & & $\begin{array}{c}\text { Orden } \\
\text { cero }\end{array}$ & $\begin{array}{l}\text { Par- } \\
\text { cial }\end{array}$ & $\begin{array}{l}\text { Semi- } \\
\text { parcial }\end{array}$ & $\begin{array}{c}\text { Tole- } \\
\text { rancia }\end{array}$ & FIV \\
\hline (Constante) & 74.964 & 6.617 & & 11.328 & .000 & & & & & \\
\hline Edad & -.062 & .070 & -.060 & -.884 & .378 & -.071 & -.062 & -.058 & .912 & 1.096 \\
\hline $\begin{array}{l}\text { Satisfacción } \\
\text { marital }\end{array}$ & .189 & .083 & .191 & 2.278 & .024 & .162 & .157 & .149 & .606 & 1.649 \\
\hline $\begin{array}{l}\text { Satisfacción } \\
\text { familiar }\end{array}$ & .249 & .079 & .244 & 3.156 & .002 & .245 & .216 & .206 & .714 & 1.400 \\
\hline $\begin{array}{l}\text { Integración } \\
\text { familiar }\end{array}$ & -.070 & .026 & -.220 & -2.723 & .007 & -.030 & -.187 & -.178 & .656 & 1.525 \\
\hline $\begin{array}{l}\text { Agota- } \\
\text { miento }\end{array}$ & 1.008 & .905 & .560 & 1.114 & .267 & -.161 & .078 & .073 & .017 & 59.139 \\
\hline $\begin{array}{l}\text { Despersona- } \\
\text { lización }\end{array}$ & 1.311 & .913 & .441 & 1.436 & .153 & -.108 & .100 & .094 & .045 & 22.059 \\
\hline $\begin{array}{l}\text { Baja } \\
\text { realización }\end{array}$ & 1.315 & .895 & .752 & 1.468 & .144 & -.010 & .102 & .096 & .016 & 61.494 \\
\hline Burnout & -1.271 & .904 & -1.147 & -1.405 & .161 & -.150 & -.098 & -.092 & .006 & 155.808 \\
\hline
\end{tabular}


En la Tabla 10, se tienen los resultados del segundo modelo, en el que las variables predictoras son la edad, la satisfacción marital, la satisfacción familiar, la integración familiar, la satisfacción intrínseca, la satisfacción extrínseca y la satisfacción laboral; mientras que el síndrome de burnout es la variable dependiente. Este segundo modelo también resultó significativo $(\mathrm{p}<0.022)$.

Tabla 10.

Resumen del modelo 2

\begin{tabular}{|ccccccccc|}
\hline R & R cuadrado & $\begin{array}{c}\text { R cuadrado } \\
\text { corregida }\end{array}$ & $\begin{array}{c}\text { Error típ. } \\
\text { de la es- } \\
\text { timación }\end{array}$ & $\begin{array}{c}\text { Cambio en R } \\
\text { cuadrado }\end{array}$ & $\begin{array}{c}\text { Cambio } \\
\text { en F }\end{array}$ & gl1 & gl2 & $\begin{array}{c}\text { Sig. cambio } \\
\text { en F }\end{array}$ \\
\hline 0.262 & 0.069 & 0.042 & 17.596 & 0.069 & 2.538 & 6 & 206 & 0.022 \\
\hline
\end{tabular}

Variables predictoras: edad, satisfacción marital, satisfacción familiar, integración familiar, satisfacción intrínseca, satisfacción extrínseca, satisfacción laboral.

Variable dependiente: síndrome de burnout.

La Tabla 11 nos muestra el análisis de varianza del segundo modelo, en el que el síndrome de burnout es la variable dependiente.

Tabla 11.

\section{Análisis de varianza del modelo 2}

\begin{tabular}{|cccccc|}
\hline Modelo & $\begin{array}{c}\text { Suma de } \\
\text { cuadrados }\end{array}$ & gl & Media cuadrática & F & Sig. \\
\hline Regresión & 4714.668 & 6 & 785.778 & 2.538 & 0.022 \\
Residual & 63782.525 & 206 & 309.624 & & \\
Total & 68497.319 & 212 & & & \\
\hline
\end{tabular}

Finalmente, la Tabla 12 nos muestra que solo la satisfacción familiar predice el síndrome de burnout, ya que el valor del coeficiente beta estandarizado es el que más se acerca a la significancia estadística $(\mathrm{p}<0.056)$. Su valor es, sin embargo, negativo, lo que quiere decir que a menor satisfacción familiar, mayor será el síndrome de burnout. 
Tabla 12.

Coeficientes betas estandarizados de las variables predictoras del modelo 2

\begin{tabular}{|c|c|c|c|c|c|c|c|c|c|c|}
\hline \multirow{2}{*}{ Modelo 2} & \multicolumn{2}{|c|}{$\begin{array}{l}\text { Coeficientes no } \\
\text { estandarizados }\end{array}$} & \multirow{2}{*}{$\begin{array}{c}\begin{array}{c}\text { Coeficien- } \\
\text { tes estan- } \\
\text { darizados }\end{array} \\
\text { Beta }\end{array}$} & \multirow{2}{*}{$\mathrm{t}$} & \multirow{2}{*}{ Sig. } & \multicolumn{3}{|c|}{ Correlaciones } & \multicolumn{2}{|c|}{$\begin{array}{l}\text { Estadísticos de } \\
\text { colinealidad }\end{array}$} \\
\hline & B & $\begin{array}{l}\text { Error } \\
\text { típico }\end{array}$ & & & & $\begin{array}{l}\text { Orden } \\
\text { cero }\end{array}$ & $\begin{array}{l}\text { Par- } \\
\text { cial }\end{array}$ & $\begin{array}{l}\text { Semipar- } \\
\text { cial }\end{array}$ & $\begin{array}{l}\text { Toleran- } \\
\text { cia }\end{array}$ & FIV \\
\hline (Constante) & 69.262 & 5.948 & & 11.646 & .000 & & & & & \\
\hline Edad & .071 & .064 & .077 & 1.113 & .267 & .082 & .077 & .075 & .945 & 1.058 \\
\hline $\begin{array}{l}\text { Satisfacción } \\
\text { marital }\end{array}$ & -.087 & .076 & -.098 & -1.143 & .254 & -.120 & -.079 & -.077 & .617 & 1.622 \\
\hline $\begin{array}{l}\text { Satisfacción } \\
\text { familiar }\end{array}$ & -.142 & .074 & -.154 & -1.923 & .056 & -.185 & -.133 & -.129 & .709 & 1.411 \\
\hline $\begin{array}{l}\text { Integración } \\
\text { familiar }\end{array}$ & .028 & .024 & .098 & 1.168 & .244 & -.008 & .081 & .078 & .643 & 1.555 \\
\hline $\begin{array}{l}\text { Satisfacción } \\
\text { intrínseca }\end{array}$ & .255 & .286 & .139 & .891 & .374 & -.132 & .062 & .060 & .186 & 5.370 \\
\hline $\begin{array}{l}\text { Satisfacción } \\
\text { extrínseca }\end{array}$ & -.394 & .258 & -.239 & -1.527 & .128 & -.173 & -.106 & -.103 & .184 & 5.440 \\
\hline
\end{tabular}

\section{Discusión}

El trabajo y la familia constituyen un binomio que contribuye a la trascendencia del ser humano. La familia nos permite trascender (Lukas, 2010) al igual que el trabajo (Ferreiro \& Alcázar, 2012) porque ambas son fuente de bienestar, desarrollo personal y autorrealización. Tanto en el trabajo como en la familia se establecen vínculos humanos y compromisos que enriquecen la vida emocional de la persona y dotan de sentido su existencia, y en esa medida son fuente de satisfacción.

De ahí que la satisfacción familiar puede relacionarse también con la satisfacción laboral. Al respecto, se reconocen relaciones bidireccionales entre ambas variables, ya que por un lado la familia puede afectar el trabajo, pero el trabajo también puede afectar a la familia. Asimismo, también hay evidencia de que entre los problemas que se desprenden del binomio familia-trabajo una de las causas es el conflicto de roles (Guerrero \& Puerto, 2007). Por ejemplo, más horas de trabajo restan tiempo con la familia, lo que aumenta la probabilidad de que ocurran conflictos en casa; o una discusión con la pareja puede hacer que el trabajo se torne agobiante.

Lamentablemente, pocos estudios se han centrado en la satisfacción familiar relacionándola con el trabajo (Prado \& Del Águila, 2010). En ese sentido, los estudios 
de Belén Salvatierra $(2001,2011)$ han identificado una problemática muy propia del minero peruano que afecta tanto el trabajo como a la familia, en un círculo vicioso que termina por desgastar su desempeño en ambos escenarios. Adicionalmente, hemos encontrado que en los residentes de Arequipa, diversas variables socioeconómicas se relacionan con la integración familiar, como, por ejemplo, los ingresos mensuales, el grado de instrucción y el nivel socioeconómico; lo que da cuenta de la relevancia de ciertas variables sociolaborales en la familia (Castro et al., 2013).

Por otro lado, las relaciones entre la satisfacción laboral y el estrés están bien fundamentadas (López-Araújo et al, 2007). El síndrome de burnout es una modalidad de estrés crónico en el trabajo, que se desarrolla sobre todo en profesiones de servicios humanos (Arias y Jiménez, 2012a), con la triada de síntomas como el agotamiento emocional, la despersonalización y la baja realización personal. Nuestros estudios señalan que un amplio grupo de profesionales registra niveles severos y moderados del síndrome de burnout (Arias y Jiménez, 2012a; Arias, Riveros y Salas, 2012; Arias y Zegarra, 2013; Arias, Masías y Justo, 2014). Aunque entre los factores causales se han estudiado más los de corte laboral, no se puede obviar el papel que la familia tendría en la sobrecarga laboral y el distrés del trabajador.

No hay estudios en el Perú que analicen las relaciones entre la satisfacción marital, la satisfacción familiar, la integración familiar, la satisfacción laboral y el síndrome de burnout; aunque se reconoce la relevancia de todas estas variables en la salud del trabajador y se proponen algunas iniciativas de parte de la empresa para paliar los efectos negativos que pueden tener ciertos aspectos del contexto familiar en el rendimiento de los trabajadores (Sanz, 2011; Donati, 2015). De modo que para la presente investigación se planteó el análisis de las relaciones entre nuestras variables de estudio.

Un primer resultado es que la edad no se relaciona con ninguna de las variables señaladas. En ese sentido, se ha reportado que los trabajadores más jóvenes valoran más su trabajo que la familia, y los trabajadores de más edad valoran más a su familia que el trabajo (Golik, 2013). En general, se aprecia que los jóvenes retrasan cada vez más la edad en la que se casan y forman sus familias, precisamente para reducir el impacto de la familia en el trabajo (Pérez, Díaz, Vázquez, Olivera y Martínez, 2014).

Por otro lado, la satisfacción marital se relaciona con la satisfacción familiar, mas no con la integración familiar. Además, la satisfacción familiar se relaciona con la satisfacción extrínseca y la satisfacción laboral. La satisfacción extrínseca, a su vez, se relaciona con la satisfacción intrínseca y con la satisfacción laboral. En el primer caso, esto podría deberse a que, como han reportado Boluarte y Merino (2015), las dimensiones de la escala de satisfacción laboral de Warr, Cook y Wall no discrimi- 
nan adecuadamente entre los constructos de satisfacción intrínseca y extrínseca. Con respecto al síndrome de burnout, el agotamiento emocional se relaciona fuertemente con el síndrome y con la despersonalización; asimismo, la despersonalización y la baja realización personal se relacionan moderadamente con el síndrome, pero negativamente entre sí. Estas inconsistencias han sido también reportadas por estudios hechos con poblaciones de Lima (Fernández \& Merino, 2014; Fernández, Juárez \& Merino, 2015); mientras que en Arequipa, estamos trabajando en el análisis psicométrico del Inventario de Burnout de Maslach (MBI, por sus siglas en inglés) con grupos representativos de profesionales de diversas especialidades.

A nivel comparativo, tenemos que se encontraron diferencias significativas entre varones y mujeres en satisfacción marital, integración familiar y síndrome de burnout, y son los varones quienes reportan mayor satisfacción marital e integración familiar, y las mujeres, las que reportan mayores niveles del síndrome de burnout. Esto podría ser un indicador de que las mujeres vivencian un mayor conflicto familia-trabajo, debido a que asumen responsabilidades en mayor medida que los varones al responder tanto a las demandas familiares como a las laborales, mientras que los varones asumen más responsabilidades laborales (Sanz, 2011; González, 2011). Es importante, entonces, brindar el apoyo necesario a las mujeres para que puedan cumplir mejor sus roles de esposa, madre y trabajadora. Para ello, diversas prácticas como permisos parentales, horarios flexibles y teletrabajo son muy útiles (Donati, 2015). Curiosamente, en la empresa donde se recogieron los datos sí se aplican estas medidas con las trabajadoras; además de haber un lactario, brindar bonos económicos por el nacimiento de los hijos o bonos mensuales por el número de hijos, etc. Esto sugiere, entonces, que las fuentes de distrés pueden darse más en la casa que en el trabajo, ya que además han tenido puntajes más bajos en la satisfacción marital y la familiar. Ello supone analizar más a fondo esta problemática y propiciar una visión más integral del conflicto familia-trabajo, en lugar de verla como la simple problemática de dos escenarios distintos pero complementarios. Esto, como dice Granados (2015), implica dar un nuevo enfoque al problema y desarrollar propuestas sinérgicas, que no solo vengan del trabajo a la familia, sino viceversa.

También se han registrado diferencias entre los administrativos y los docentes universitarios. Mientras los docentes tienen mayores niveles de satisfacción marital, los administrativos tienen mayores niveles de baja realización personal y del síndrome de burnout. Al respecto, varios estudios latinoamericanos han reportado que los docentes universitarios tienen escasos niveles del síndrome de burnout (Caballero, González, Mercado, Llanos, Bermejo \& Vergel, 2009; Silva, Gil-Monte, Possobon \& Bovi, 2012). De hecho, se sabe que el síndrome de burnout es más severo en los profesores de nivel escolar que en aquellos de nivel universitario (Arias y Jiménez, 2012b); mientras que otros estudios reportan que tener carga académica 
y desempeñar funciones de gestión en la universidad acarrean mayores niveles de estrés (López-Vilchez \& Gil-Monte, 2015). Asimismo, en el estudio de García, González, Aldrete, Acosta y León (2014) se encontró que la tercera parte de 447 personas que laboran como personal administrativo universitario tenía niveles adecuados de satisfacción laboral, pero más de la mitad no tenía disposición para trabajar ni disfrutaba del tiempo de trabajo, y tampoco reflejó equilibrio o armonía entre la vida laboral y la familiar. En un reporte previo, encontramos que los profesores universitarios tenían menos niveles de espiritualidad en el trabajo en comparación con los administrativos, y que la felicidad se relacionaba con la espiritualidad (Arias, Masías, Muñoz \& Arpasi, 2013).

En consecuencia, una posible causa de los valores encontrados de baja realización personal entre los administrativos es su grado de instrucción, que es menor que el de los profesores universitarios, y también los ingresos que reciben. De hecho, al comparar las variables de estudio en función del sueldo, encontramos que en la satisfacción laboral y las dimensiones del síndrome de burnout quienes tienen menos ingresos mensuales también tienen mayores niveles de insatisfacción (intrínseca, extrínseca y laboral), agotamiento emocional, despersonalización y baja realización personal. Al comparar las variables en función de los años de servicio, quienes tienen mayor tiempo de servicio tienen niveles significativamente mayores de agotamiento, despersonalización y baja realización personal. Esto se explica porque a mayor tiempo de trabajo se está expuesto de manera más prolongada a los estresores laborales (Gil-Monte \& Peiró, 1999).

Finalmente, al hacer el análisis de regresión lineal, encontramos que la satisfacción marital y la satisfacción familiar predicen positivamente la satisfacción laboral, mientras que la integración familiar la predice de manera negativa. Esto último podría explicarse por los bajos niveles de integración familiar reportados en la muestra de esta investigación. No obstante, también reflejan que los problemas familiares afectan negativamente el trabajo. Asimismo, los coeficientes betas de la satisfacción familiar se acercaron mucho al nivel de significancia estadística aceptable, como predictor negativo del síndrome de burnout, lo que quiere decir que mientras menor sea la satisfacción familiar mayor será el síndrome de burnout. Nuestros resultados son consistentes con otros estudios; por ejemplo, en una muestra de 105 académicos de una universidad estatal chilena, se encontró que los que tenían mayores niveles de adicción al trabajo tenían menos niveles de satisfacción laboral, y que los niveles de satisfacción familiar fueron menores en los adictos al trabajo (Vega \& Moyano, 2010). Así también, en el estudio de Martínez, López y García (2013), se encontró que las mujeres fueron las trabajadoras universitarias más afectadas por el riesgo psicosocial en el trabajo y que una adecuada organización del tiempo libre y el trabajo doméstico se asociaba con menos daños psicosociales. 
En general, se ha visto que ciertos aspectos propios de la organización del trabajo universitario son muy demandantes y estresantes, tales como la multiplicidad de tareas, la sobrecarga laboral, los espacios inadecuados, la falta de tiempo y la remuneración, y también son fuentes de riesgo psicosocial en los docentes universitarios (Botero, 2012). Otros estudios muestran que a pesar de los niveles elevados de burnout en los profesores universitarios, ellos cuentan con niveles adecuados de compromiso en su trabajo (Ruíz, Pando, Aranda y Almeida, 2014). Para el caso de los trabajadores administrativos, se trata de una población poco atendida, ya que la mayoría de estudios se centra en los profesores universitarios. Por ello, es importante capacitarlos en técnicas de afrontamiento (Labrador, 1996), además de evaluar permanentemente los factores de riesgo psicosocial en la universidad (Leibovich \& Schufer, 2006) y de promover la gestión del talento humano (Chiavenato, 2009) con enfoques en la familia (Granados, 2015). No podemos olvidar que los factores de riesgo psicosocial, y sobre todo el síndrome de burnout, son una realidad muy frecuente que afecta a los trabajadores en los contextos latinoamericanos (Moreno, Garrosa, Benavides-Perea \& Gálvez, 2003), y que el estrés crónico puede tener consecuencias muy perjudiciales para la salud tanto física como mental (Moscoso, 2010).

Para terminar, solo nos queda señalar que es necesario profundizar en los temas de salud ocupacional en el ámbito nacional, así como disponer de mejores instrumentos de evaluación, ya que de lo contrario la investigación en escenarios laborales podría encontrarse con diversos obstáculos. Asimismo, es cada vez más relevante prestar atención a las relaciones entre la familia y el trabajo, ya que, sean conflictivas o no, constituyen un espacio de convivencia que trasciende en la vida de las personas.

\section{Referencias}

Alarcón, R. (2000). Variables psicológicas asociadas a la felicidad. Persona, 3, 147-157.

Alarcón, R. (2001). Relaciones entre felicidad, género, edad y estado conyugal. Revista de Psicología de la PUCP, 19(1), 27-46.

Alarcón, R. (2002). Fuentes de felicidad: ¿Qué hace a la gente feliz? Revista de Psicología de la PUCP, 2o(2), 169-196.

Alarcón, R. (2006). Desarrollo de una escala factorial para medir la felicidad. Revista Interamericana de Psicología, 40(1), 99-106.

Alarcón, R. (2009). Psicología de la felicidad. Lima: Universidad Ricardo Palma.

Alarcón, R. (2014). Funcionamiento familiar y sus relaciones con la felicidad. Revista Peruana de Psicología y Trabajo Social, 3(1), 61-74. 
Arias, W. L. (2012a). Algunas consideraciones sobre la familia y la crianza desde un enfoque sistémico. Revista de Psicología de Arequipa, 2(1), 32-46.

Arias, W. L. (2012b). Estrés laboral y consumo de sustancias psicoactivas (SPA) desde un enfoque de la salud ocupacional. Revista Peruana de Psicología y Trabajo Social, $1(1)$, 107-118.

Arias, W. L. (2012c). Estrés laboral en trabajadores desde el enfoque de los sucesos vitales. Revista Cubana de Salud Pública, 38(4), 525-535.

Arias, W. L. (2013a). Clima organizacional en ocho empresas de Arequipa. Illustro, 4, 39-56.

Arias, W. L. (2013b). Agresión y violencia en la adolescencia: La importancia de la familia. Avances en Psicología, 21(1), 23-34.

Arias, W. L. (2015). Síndrome de burnout y afrontamiento. Arequipa: Adrus.

Arias, W. L., \& Arias, G. (2014). Relación entre el clima organizacional y la satisfacción laboral en una pequeña empresa del sector privado. Ciencia E Trabajo, 16(51), 185-191.

Arias, W. L., Castro, R., Domínguez, S., Masías, M. A., Canales, F., Castilla, S., \& Castilla, S. (2013). Construcción de un inventario de integración familiar. Avances en Psicología, 21(2), 195-206.

Arias, W. L., \& Jiménez, N. A. (2012a). Estudio comparativo del síndrome de burnout en enfermeras, policías y docentes de Arequipa. Revista de Psicología de Arequipa, 2(2), 180-206.

Arias, W. L., \& Jiménez, N. A. (2012b). Estrés crónico en el trabajo: Estudios del síndrome de burnout en Arequipa. Arequipa: Universidad Católica San Pablo.

Arias, W. L., Riveros, P. J., \& Salas, X. S. (2012). Espiritualidad en el ambiente laboral, estrés crónico (burnout) y estilos de afrontamiento en trabajadores de una empresa de servicios educativos. Ciencia E Trabajo, 14(44), 195-200.

Arias, W. L., \& Justo, O. (2013). Satisfacción laboral en trabajadores de dos tiendas por departamento: Un estudio comparativo. Ciencia \& Trabajo, 15(47), 41-46.

Arias, W. L., Justo, O., \& Muñoz, E. (2014). Síndrome de burnout y estilos de afrontamiento en psicólogos de la ciudad de Arequipa. Revista de Psicología. Universidad Católica San Pablo, 4(4), 25-42.

Arias, W. L., \& Zegarra, J. (2013). Clima organizacional, síndrome de burnout y afrontamiento en trabajadores de un hospital oncológico de Arequipa. Revista de Psicología de la UCV, 15(1), 37-54.

Arias, W. L., Masías, M. A., Muñoz, E., \& Arpasi, M. (2013). Espiritualidad en el ambiente laboral y su relación con la felicidad del trabajador. Revista de Investigación de la UCSP, 4, 9-33.

Arias, W. L., Masías, M. A., \& Justo, O. (2014). Felicidad, síndrome de burnout y 
estilos de afrontamiento en una empresa privada. Avances en Psicología, 22(1), 75-88.

Arias, W. L., Masías, M. A., Salas, X. S., Yépez, L., \& Justo, O. (2014). Integración familiar y felicidad en la ciudad de Arequipa. Revista de Psicología de Arequipa, 4(2), 189-199.

Arias, W. L., \& Ceballos, K. (2016). Síndrome de burnout, satisfacción laboral e integración familiar en trabajadores de una tienda por departamento de Arequipa. Illustro (trabajo sometido a revisión).

Arias, W. L., Quispe, A. C., \& Ceballos, K. (2016). Estructura familiar y nivel de logro en niños y niñas de instituciones educativas públicas de Arequipa. Perspectiva de Familia, 1, 35-62.

Atalaya, M. (2001). El estrés laboral y su influencia en el trabajo. Industrial Data, 4(2), 25-36.

Barrón, A., \& Martínez-Íñigo, D. (1999). Atribuciones de causalidad y responsabilidad en una muestra de casados y divorciados. Psicothema, 11(3), 551-560.

Beltrán, A. (2013). El tiempo de la familia es un recurso escaso: ¿cómo afecta su distribución en el desempeño escolar? Apuntes, 40(72), 117-156.

Boada, J., De Diego, R., \& Agulló, E. (2004). El burnout y las manifestaciones psicosomáticas como consecuentes del clima organizacional y de la motivación laboral. Psicothema, 16(1), 125-131.

Boluarte, A., \& Merino, C. (2015). Versión breve de la escala de satisfacción laboral: evaluación estructural y distribución de sus puntajes. Liberabit, 21(2), 235-243.

Botero, C. C. (2012). Riesgo psicosocial intralaboral y burnout en docentes universitarios de algunos países latinoamericanos. Cuadernos de Administración, 28(48), 117-132.

Caballero, C., González, O., Mercado, D., Llanos, C., Bermejo, Y., \& Vergel, C. (2009). Prevalencia del síndrome de burnout y su correlación con factores psicosociales en docentes de una institución universitaria privada de la ciudad de Barranquilla. Psicogente, 12(21), 142-157.

Campiglio, L. (2015). El valor económico de la familia. En S. Kampowski \& G. Gallazzi (Comp.), Familia y desarrollo sostenible (pp. 203-224). Arequipa: Universidad Católica San Pablo.

Castañeda-Rentería, L. I. (2015). Referentes, tensiones y rupturas identitarias. Mujeres profesionistas y sus familias de origen. Avances en Psicología, 23(2), 191-201.

Castro, R., Arias, W. L., Dominguez, S., Masías, M. A., Salas, X., Canales, F., \& Flores, A. (2013). Integración familiar y variables socioeconómicas en Arequipa metropolitana. Revista de Investigación de la UCSP, 4, 35-65.

Chiavenato, I. (2009). Gestión del talento humano. México: McGraw-Hill. 
Cuervo, J. J. (2013). Parejas viables que perduran en el tiempo. Diversitas. Perspectivas en Psicología, 9(2), 257-270.

Díaz-Morales, J. F., Quiroga, M. A., Escribano, C., \& Delgado, P. (2009). Emparejamiento selectivo en temperamento e inteligencia y su relación con la satisfacción marital. Psicothema, 21(2), 262-267.

Dominguez, S., Aravena, S., Ramírez, F., \& Yauri, C. (2013). Propiedades psicométricas de la escala de calidad de interacción familiar en escolares de Lima. Revista de Psicología de la UCV, 15(1), 55-77.

Donati, P. (2015). La familia, capital social: Las políticas para promover el capital social familiar como prerrequisito de un desarrollo sostenible. En G. Gallazzi \& S. Kampowski (Comp.), Familia y desarrollo sostenible (pp. 135-183). Arequipa: Universidad Católica San Pablo.

Eguiluz, L. L., Calvo, R. M., \& De la Orta, D. (2012). Relación entre la percepción de la satisfacción marital, sexual y la comunicación en parejas. Revista Peruana de Psicología y Trabajo Social, 1(1), 15-28.

Fernández, M., \& Merino, C. (2014). Error de medición alrededor de los puntos de corte en el MBI-GS. Liberabit, 20(2), 209-218.

Fernández, M., Juárez, A., \& Merino, C. (2015). Análisis estructural de invarianza de medición del MBI-GS en trabajadores peruanos. Liberabit, 21(1), 9-20.

Ferreiro, P., \& Alcázar, M. (2012). Gobierno de personas en la empresa. Lima: Planeta.

Gamero, H. (2013). La satisfacción laboral como dimensión de la felicidad. Ciencia E Trabajo, 15(47), 94-102.

García, M. A., González, R., Aldrete, M. G., Acosta, M., \& León, S. G. (2014). Relación entre calidad de vida en el trabajo y síntomas de estrés en el personal administrativo universitario. Ciencia $\mathcal{E}$ Trabajo, 16(50), 97-102.

Gil-Monte, P. R., \& Peiró, J. M. (1999). Perspectivas teóricas y modelos interpretativos para el estudio del síndrome de quemarse por el trabajo. Anales de Psicología, 15(2), 261-268.

Golik, M. (2013). Las expectativas de equilibrio entre vida laboral y vida privada y las elecciones laborales de la nueva generación. Cuadernos de Administración, 26(46), 107-133.

Gómez, A., Benítez, C., Guillén, C., Gala, F. J., \& Lupiani, M. (200o). Motivación y satisfacción laboral. En C. Guillén \& R. Guil (Coord.), Psicología del trabajo para relaciones laborales (pp. 195-209). Madrid: McGraw-Hill.

González, M. F. (2011). Salud laboral y género. Apuntes para la incorporación de la perspectiva de género en el ámbito de la prevención de riesgos laborales. Revista de Medicina y Seguridad en el Trabajo, 57, 89-114. 
Granados, J. (2015). Familia y trabajo: Una propuesta sinérgica. En G. Gallazzi y S. Kampowski (Comp.), Familia y desarrollo sostenible (pp. 61-81). Arequipa: Universidad Católica San Pablo.

Guerrero, J., \& Puerto, Y. I. (2007). Productividad, trabajo y salud: La perspectiva psicosocial. Revista Colombiana de Psicología, 16, 203-234.

Guzmán-González, M., Alfaro, I., \& Armenta, C. (2013). Perdón y satisfacción marital: Una mirada desde lo sistémico. Salud \& Sociedad, 4(3), 284-294.

Jyoti, J. (2013). Impact of organizational climate on job satisfaction, job commitment and intention to leave: An empirical model. Journal of Business Theory and Practice, 1(1), 66-82.

Labrador, J. F. (1996). El estrés. Nuevas técnicas para su control. España: Grupo Correo de Comunicaciones.

Latha, K., \& Janaki, D. (2012). Conceptual framework on job stress on job satisfaction among marketing employees. Global Research Advanced Journal of Management and Business Studies, 1(8), 264-269.

Lee, J. (1977). A typology of styles of loving. Personality and Social Psychology Bulletin, 3, 173-182.

Leibovich, N., \& Schufer, M. (2006). Evaluación psicológica del estrés por inestabilidad laboral. Buenos Aires: Paidós.

León, F., \& Sepúlveda, M. V. (1979). Satisfacciones e insatisfacciones herzbergianas en el trabajo. Revista Latinoamericana de Psicología, 11(1), 93-113.

León, F. (1981). The role of positive and negative outcomes in the causation of motivational forces. Journal of Applied Psychology, 66, 45-53.

López-Araújo, B., Osca, A., \& Peiró, J. M. (2007). El papel modulador de la implicación en el trabajo en la relación entre el estrés y la satisfacción laboral. Psicothema, 19(1), 81-87.

López-Vilchez, J., \& Gil-Monte, P. (2015). Sobrecarga laboral y de gestión del personal docente en el entorno universitario actual en España. Arxius, 37, 111-120.

Lukas, E. (2010). La felicidad en la familia. Buenos Aires: San Pablo.

Lwanga, F., Ndiwalna, G., Ssekabuko, J., \& Bwire Mc, J. (2014). Improving organizational performance through job satisfaction and quality assurance. Global Advanced Research Journal of Management and Business Studies, 3(7), 344-352.

Martínez-Îñigo, D. (2000). Contrastación del modelo de inversión de Rusbult en una muestra de casados y divorciados. Psichotema, 12(1), 65-69.

Martínez-Pérez, M. D., \& Osca, A. (2002). Análisis psicométrico del Inventario de Apoyo Familiar para trabajadores. Psichotema, 14(2), 310-316.

Martínez, S., López, F., \& García, O. A. (2013). Tiempo libre y trabajo doméstico en 
su relación con daños psicosociales en docentes de una universidad pública mexicana. Ciencia E Trabajo, 15(48), 165-172.

Maslach, C., \& Jackson, S. E. (1981). The measurement of experienced burnout. Journal of Occupational Behavior, 12, 99-113.

Mayorga, E., \& Ñiquen, M. (2010). Satisfacción familiar y expresión de la cólera-hostilidad en adolescentes escolares que presentan conductas antisociales. Revista de Investigaciones Psicológicas, 1(1), 87-92.

Medina, B., Reyes, C., \& Villar, T. M. (2009). La confluencia en la relación de pareja como limitante para el crecimiento personal: una visión gestáltica. Revista Mal-estar e Subjetividade, 9(4), 1103-1119.

Minuchin, S., \& Fishman, H. Ch. (1996). Técnicas de terapia familiar. México: Paidós.

Moreno, B., Garrosa, E., Benavides-Perea, A. M., \& Gálvez, M. (2003). Estudios transculturales del burnout. Los estudios transculturales Brasil-España. Revista Colombiana de Psicología, 12(1), 9-18.

Moscoso, M. (2010). El impacto del estrés crónico en la salud del individuo: Avances en psico-oncología. Persona, 13, 87-99.

Pacheco, G. (2003). Desempeño de la función educativa de los padres y su transmisión de modelos de crianza de sus familias de origen. Revista Cubana de Psicología, 20(1), 61-66.

Palma, S. (1999). Elaboración y validación de una Escala de Satisfacción Laboral SL-SPC para trabajadores de Lima metropolitana. Teoría e Investigación en Psicología, 9(1), 27-34.

Platone, M. L. (2007). El enfoque ecosistémico de terapia de familia y de pareja. Psicología, 26(1), 58-77.

Pliego, F., \& Castro, R. J. (2015). Tipos de familia y bienestar de niños y adultos. Arequipa: Universidad Católica San Pablo.

Quezada, J., Zavala, E., \& Lenti, M. (2015). Satisfacción familiar en mujeres jóvenes. Avances en Psicología, 23(2), 223-229.

Quiroga, M. A., \& Sánchez, M. P. (1997). Análisis de la insatisfacción familiar. Psicothema, 9(1), 69-92.

Pérez, K. M., Díaz, T. C., Vázquez, A., Olivera, Y., \& Martínez, J. (2014). Relación de pareja y creación de la familia propia: Procesos consustanciales al proyecto de vida y la formación profesional del joven universitario cubano. Alternativas Cubanas de Psicología, 2(4), 62-71.

Pinto, J., y Barra, E. (2015). Conflicto trabajo-familia y bienestar psicológico en trabajadores de empresas industriales de Chile. Revista Peruana de Psicología y Trabajo Social, 4(1), 15-24.

Prado, T. R., \& Del Águila, M. (2010). Ajuste y satisfacción en parejas que trabajan. Revista de Investigaciones Psicológicas, 1(1), 38-52. 
Riesco, R., \& Arela, R. (2015). Impacto de la estructura familiar en la satisfacción con los ingresos en los hogares urbanos en Perú. Economía, 38(76), 51-76.

Ríos, J. A. (2005). Los ciclos vitales de la familia y la pareja. ¿Crisis u oportunidades? Madrid: Editorial CCS.

Romero, K., \& Kerstenetzky, C. L. (2015). Entre altruismo e o familismo: a agenda parlamentar femenina e as políticas familia-trabalho (Brasil, 2003-2013). Revista Brasileira de Ciência Política, 18, 119-146.

Rubio, C., Osca, A., Recio, P., Urien, B., \& Peiró, J. M. (2015). Work-family conflict, self-efficacy, and emotional exhaustion: A test of longitudinal effects. Journal of Work and Organizational Psychology, 31, 147-154.

Ruíz, D., Pando, M., Aranda, C., \& Almeida, C. (2014). Burnout y work engagement en docentes universitarios de Zacatecas. Ciencia E Trabajo, 16(50), 116-120.

Salgado, J. F., Remeseiro, C., \& Iglesias, M. (1996). Clima organizacional y satisfacción laboral en una PYME. Psicothema, 8(2), 329-335.

Salvatierra, B. (2001). Psicología del minero. Arequipa: UNSA.

Salvatierra, B. (2011). Cultura de seguridad laboral para el minero. Lima: Noceda.

Sánchez, R., \& Díaz-Loving, R. (2003). Patrones y estilos de comunicación de la pareja: Diseño de un inventario. Anales de Psicología, 19(2), 257-277.

Sanz, A. I. (2011). Conciliación y salud laboral: ¿una relación posible? Actualidad en el estudio del conflicto trabajo-familia y la recuperación del estrés. Medicina y Seguridad del Trabajo, 57(1), 115-126.

Schneider, B., \& Snyder, R. A. (1975). Some relationships between job satisfaction and organization climate. Journal of Applied Psychology, 6o(3), 318-328.

Schultz, D. P. (1999). Psicología industrial. Bogotá: McGraw-Hill.

Selye, H. (1960). La tensión en la vida (el estrés). Buenos Aires: Editora Compañía General Fabril.

Seperak, R. A. (2014). Motivos extrínsecos, intrínsecos y trascendentes en la decisión de contraer matrimonio en casados y divorciados (tesis de pregrado). Universidad Católica San Pablo, Arequipa.

Silva, L. da, Gil-Monte, P., Possobon, R., \& Bovi, C. M. (2012). Prevalência da síndrome de burnout en uma amostra de profesores universitarios brasileiros. Psicologia: Reflexão e Crítica, 26(4), 636-642.

Valdez, J. L., González-Arratia, N. I., Arce, J., \& López, M. C. (2007). La elección real e ideal de pareja: un estudio con parejas establecidas. Revista Interamericana de Psicología, 41(3), 305-311.

Vega, A., \& Moyano, E. (2010). Adicción al trabajo, satisfacción laboral y familiar en académicos de una universidad estatal chilena. Salud \& Sociedad, 1(3), 222-232. 
Villegas, M., \& Mallor, P. (2012). La dimensión estructural y evolutiva en las relaciones de pareja. Acción Psicológica, 9(2), 97-108.

Villarreal-Zegarra, D., \& Paz, A. (2015). Terapia familiar sistémica: Una aproximación a la teoría y la práctica clínica. Interacciones. Revista de Avances en Psicología, 1(1), 45-55.

Zicavo, N., \& Vera, C. (2011). Incidencia del ajuste diádico y sentido del humor en la satisfacción marital. Revista de Psicología de la UCV, 13(1), 74-89. 